\title{
ANALISA ZONASI LAHAN KOSONG PADA KAWASAN PEMUKIMAN DAN INDUSTRI DITINJAU DARI ASPEK FISIK MENGGUNAKAN CITRA SATELIT ALOS TAHUN 2010 \\ (Studi Kasus : Unit Pengembangan X Wiyung Surabaya)
}

\author{
Rahadian Kartika Wijaya, Muhammad Taufik \\ Program Studi Teknik Geomatika FTSP-ITS, Kampus ITS Sukolilo, Surabaya, 60111 \\ Email : rahadiankartikawijaya@yahoo.com
}

\begin{abstract}
Abstrak
Lahan kosong di perkotaan merupakan fenomena yang menarik untuk diperhatikan. Keberadaan lahan kosong ternyata menimbulkan persoalan-persoalan yang serius diperkotaan. Lahan kosong dapat mendorong peningkatan harga lahan secara cepat karena kesediaan lahan menjadi berkurang sedangkan permintaan akan lahan terus bertambah. Wilayah Unit Pengembangan X Wiyung yang terdiri dari Kecamatan Wiyung, Kecamatan Lakarsantri dan Kecamatan Karang Pilang, Surabaya yang menjadi arahan pengembangan kawasan permukiman, dan industri menurut Rencana Detil Tata Ruang Kota (RDTRK) Unit Pengembangan X Wiyung Surabaya.

Analisa lahan kosong pada wilayah tersebut untuk memaksimalkan potensi lahan kosong sesuai dengan kebutuhan, arahan Rencana Detail Tata Ruang Kota (RDTRK) Unit Pengembangan X Wiyung Surabaya, dengan memanfaatkan data citra satelit ALOS tahun 2010. Hasil analisa tutupan lahan diperoleh 4 kelas yaitu badan air, ladang, pemukiman, dan sawah. Pada Unit Pengembangan X Wiyung memiliki lahan kosong yang terdiri dari sawah dan ladang yang terdapat di kawasan tersebut yang belum dimanfaatkan sesuai arahan RDTRK sebesar $1631.486 \mathrm{Ha}$. Sedangkan pada kawasan industri, Lahan kosong yang terdapat di kawasan tersebut yang belum dimanfaatkan sesuai arahan RDTRK sebesar $77.052 \mathrm{Ha}$.
\end{abstract}

Kata Kunci : Lahan Kosong, RDTRK, Unit Pengembangan, ALOS

\section{PENDAHULUAN}

\section{Latar Belakang}

Lahan kosong di perkotaan merupakan fenomena yang menarik untuk diperhatikan. Secara teoritis lahan harus dimanfaatkan secara optimal karena ketersediaan terbatas, tetapi permintaannya terus bertambah. Kemudian secara normatif lahan memiliki fungsi sosial, dimana pemanfaatannya harus memberikan manfaat sebesar-besarnya bagi masyarakat (UUPA No.5 Tahun 1960). Akan tetapi keberadaan lahan kosong justru memutarbalikkan sisi teoritis dan normatif tersebut. Adanya lahan kosong justru menunjukkan terjadinya inefisiensi pemanfaatan lahan dan tidak mendukung fungsi sosial lahan. Pada akhirnya lahan kosong dapat menghambat pembangunan kota.

Keberadaan lahan kosong ternyata menimbulkan persoalan-persoalan yang serius diperkotaan. Lahan kosong dapat mendorong peningkatan harga lahan secara cepat karena kesediaan lahan menjadi berkurang sedangkan permintaan akan lahan terus bertambah. Sementara itu, lahan kosong umumnya tidak memiliki pemandangan fisik yang baik, kurang terawat atau ditelantarkan pemiliknya sehingga menciptakan kesan kota atau kawasan menjadi lebih buruk. Lahan kosong juga dapat menjadi potensi konflik di perkotaan karena keberadaannya berpotensi menimbulkan penyerobotan lahan sehingga dapat menimbulkan konflik antar masyarakat.

Perencanaan zonasi akan mewujudkan pemanfaatan ruang secara efektif, tepat guna, spesifik setempat dan konkret sesuai dengan rencana tata ruang wilayah, melengkapi peraturan daerah tentang kawasan pemukiman perdagangan dan jasa serta industri, mewujudkan kesatuan karakter dan meningkatkan kualitas kawasan tersebut, mengendalikan pertumbuhan fisik suatu lingkungan/kawasan, menjamin implementasi pembangunan agar sesuai dengan aspirasi dan kebutuhan masyarakat dalam pengembangan lingkungan/kawasan yang berkelanjutan serta sesuai dengan tingkat kesesuaian lahan. 
Wilayah Unit Pengembangan $X$ Wiyung yang terdiri dari Kecamatan Wiyung, Kecamatan Lakarsantri dan Kecamatan Karang Pilang, Surabaya yang menjadi arahan pengembangan kawasan permukiman, dan industri menurut Rencana Detail Tata Ruang Kota (RDTRK) Unit Pengembangan $X$ Wiyung Surabaya, dimana masih terdapat banyak lahan kosong yang belum dimanfaatkan sesuai dengan arahan tersebut.

Oleh karena itu, diperlukan analisa lahan kosong pada wilayah tersebut untuk memaksimalkan potensi lahan kosong sesuai dengan kebutuhan, arahan Rencana Detail Tata Ruang Kota (RDTRK) Unit Pengembangan X Wiyung Surabaya, serta tingkat kesesuaian lahan dengan memanfaatkan data citra satelit ALOS tahun 2010 dan peta RDTRK pada penelitian ini.

\section{Rumusan Permasalahan}

Perumusan masalah tugas akhir ini adalah bagaimana menganalisa zonasi lahan kosong pada kawasan pemukiman dan industri yang ditinjau dari tingkat kesesuaian penggunaan lahan di wilayah Unit Pengembangan X Wiyung, Surabaya dengan memanfaatkan data citra satelit ALOS tahun 2010 dengan acuan Rencana Detail Tata Ruang Kota (RDTRK) Unit Pengembangan $X$ Wiyung.

\section{Batasan Masalah/Ruang Lingkup}

Adapun batasan masalah yang diajukan dalam penelitian ini adalah sebagai berikut:

Studi kasus atau wilayah pengamatan adalah wilayah Unit Pengembangan $X$ Wiyung, (Kecamatan Wiyung, Lakarsantri dan Karang Pilang) Surabaya.

Data yang digunakan adalah Citra ALOS tahun 2010.

Peta yang digunakan sebagai acuan adalah Peta Rencana Detail Tata Ruang Kota (RDTRK) Unit Pengembangan X Wiyung tahun 2009 produk dari Badan Perencanaan Pembangunan Kota (BAPPEKO) Surabaya.

\section{Tujuan}

Tujuan penelitian ini adalah untuk mengetahui sebaran lahan kosong di wilayah tersebut serta untuk menganalisa zonasi lahan kosong yang ditinjau dari tingkat kesesuaian penggunaan lahan yang dapat menjadi pertimbangan dalam mengembangkan wilayah Unit Pengembangan $X$ Wiyung Surabaya.

\section{Manfaat}

Manfaat dari penelitia ini adalah sebagai masukan bagi Pemerintah Kota Surabaya dan evaluasi dalam perencanaan pengembangan pada kawasan pemukiman, dan industri di wilayah Unit Pengembangan X Wiyung Surabaya.

\section{METODOLOGI PENELITIAN}

\section{Lokasi Penelitian}

Lokasi penelitian tugas akhir ini mengambil daerah studi di wilayah Unit Pengembangan $X$ Wiyung Kota Surabaya, Jawa Timur. Lokasi penelitian ini menurut RDTRK UP $X$ Wiyung memiliki LUASAN seluas 4.219,63 $\mathrm{Ha}$, yang terletak pada koordinat $7^{\circ} 18^{\prime} 20^{\prime \prime} \mathrm{LS}-7^{\circ} 20^{\prime} 45^{\prime \prime}$ LS dan $112^{\circ} 38^{\prime} 55^{\prime \prime}$ BT - $112^{\circ} 41^{\prime} 32^{\prime \prime}$ BT yang seperti ditunjukkan oleh gambar dibawah ini:

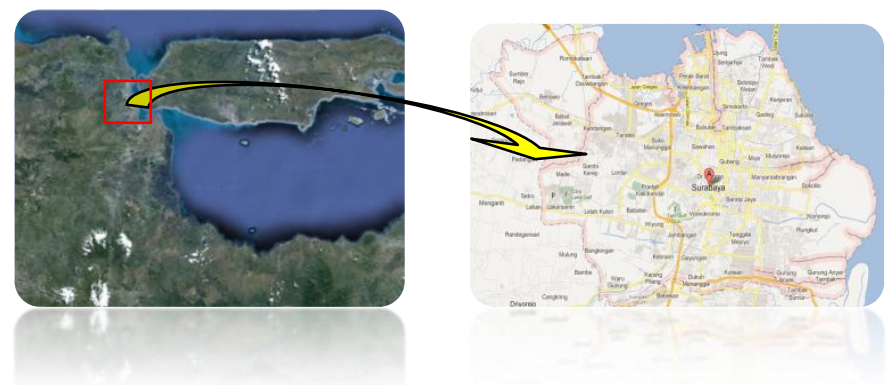

Gambar 1. Lokasi Penelitian

(Bappeda Pacitan, 2008)

\section{Data Dan Peralatan}

\section{- Data}

Data yang digunakan dalam penelitian ini adalah:

1. Data Citra satelit ALOS-AVNIR2 bulan September 2010.

2. Citra Landsat Orthorektifikasi.

3. cPeta yang digunakan adalah Peta hasil RDTRK skala 1 : 5000 Unit Pengembangan $X$ Wiyung tahun 2002 produk dari BAPPEKO Surabaya.

\section{- Peralatan}


Peralatan yang digunakan dalam penelitian ini adalah:

1. Perangkat Keras (Hardware)
a. Water Checker TROLL 9500 Multi Parameter Series S/N 47916 digunakan untuk mengetahui nilai TSS
b. GPS navigasi / handheld ketelitian 15 meter
c. Seperangkat komputer
d. Perahu motor
e. Jam digital

2. Perangkat Lunak (Software)
a. Software ENVI 4.6.1
b. Microsoft Office 2007
c. Matlab R2010a
d. ArcGis 9.0

\section{Diagram Alir}

Tahapan yang dilaksanakan dalam penelitian ini adalah :

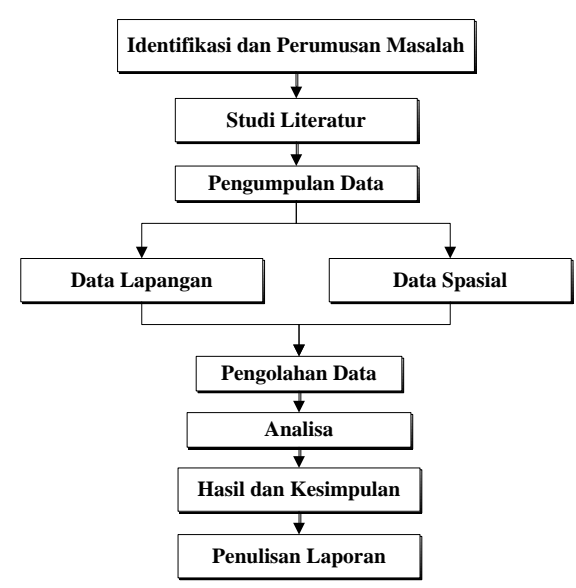

Gambar 2. Diagram Alir Penelitian

\section{Pengolahan Data}

Adapun untuk diagram alir pengolahan data adalah sebagai berikut:

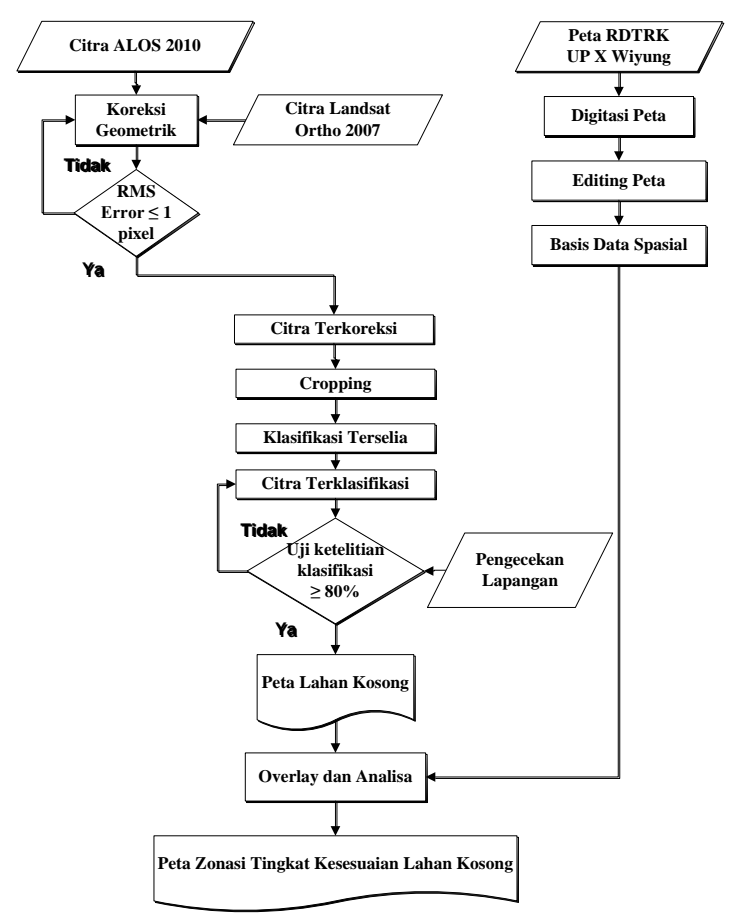

Gambar 3. Diagram Alir Pengolahan Data

Berikut ini adalah penjelasannya :

1. Citra yang digunakan dalam penelitian ini yaitu Citra Satelit ALOS ANVIR2 tahun 2010 dengan resolusi 10 meter.

2. Pengolahan data citra satelit ALOS

- Koreksi Geometrik

Koreksi yang dilakukan pada Citra satelit yang masih mengandung kesalahan geometrik atau belum mempunyai koordinat referensi yang sesuai sehingga citra yang dihasilkan belum dapat dipergunakan dan untuk menghilangkan kesalahan spasial citra yang disebabkan oleh beberapa faktor pada saat perekaman oleh sensor satelit. oleh karena itu kesalahan ini harus direduksi dengan cara :

a. Registrasi yaitu koreksi geometrik antara citra yang belum terkoreksi dengan citra yang sudah terkoreksi dalam penelitian ini citra satelit ALOS di koreksi dengan citra landsat orto. Teknik ini dilakukan jika diperlukan georeferencing (posisi citra disamakan 
dengan koordinat peta atau koordinat bumi).

b. Rektifikasi yaitu koreksi geometrik antara citra dengan peta. Koreksi geometrik yang bersifat random diselesaikan dengan analisa titik kontrol tanah (ground control point) melalui fungsi transformasi yang menghubungkan antara sistem koordinat tanah dan citra.

- Pemotongan Citra (Cropping)

Setelah tahapan koreksi geometrik dilakukan proses pemotongan citra untuk mendapatkan citra digital yang hanya meliputi daerah penelitian, supaya pemrosesan data menjadi lebih efektif. Proses pemotongan citra secara sederhana dilakukan dengan menampilkan citra berdasarkan batas daerah penelitian.

- Penajaman Citra (Image Enhancement) dilakukan untuk memperbaiki mutu citra. Proses penajaman citra sebagai berikut :

a. Data Fusion : Menggabungkan dua citra dengan area yang sama

b. Contrast Enhancement : Mengatur pencahayaan pada citra

c. Filtering : Memperbaiki tampilan citra dengan mentransformasi nilai-nilai digital citra seperti mempertajam batas area yang mempunyai nilai digital yang sama

- Klasifikasi Terselia

Klasifikasi terselia atau klasifikasi digital ini yang digunakan dalam penelitian ini yaitu dengan melibatkan interaksi analis secara intensif, dimana analis menuntun proses klasifikasi dengan identifikasi objek pada citra (training area). Sehingga pengambilan sampel perlu dilakukan dengan mempertimbangkan pola spektral pada setiap panjang gelombang tertentu, sehingga diperoleh daerah acuan yang baik untuk mewakili suatu objek tertentu. (Danoedoro, 1996).

3. Uji Ketelitian Klasifikasi

Uji ketelitian dilakukan dengan menghitung matrik konfusidan (confusion matrix) dan pengecekan lapangan langsung atau biasa disebut groundtuth dilakukan di beberapa titik di lokasi penelitian.
4. Pengolahan data peta Rencana Detail Tata Ruang Kota

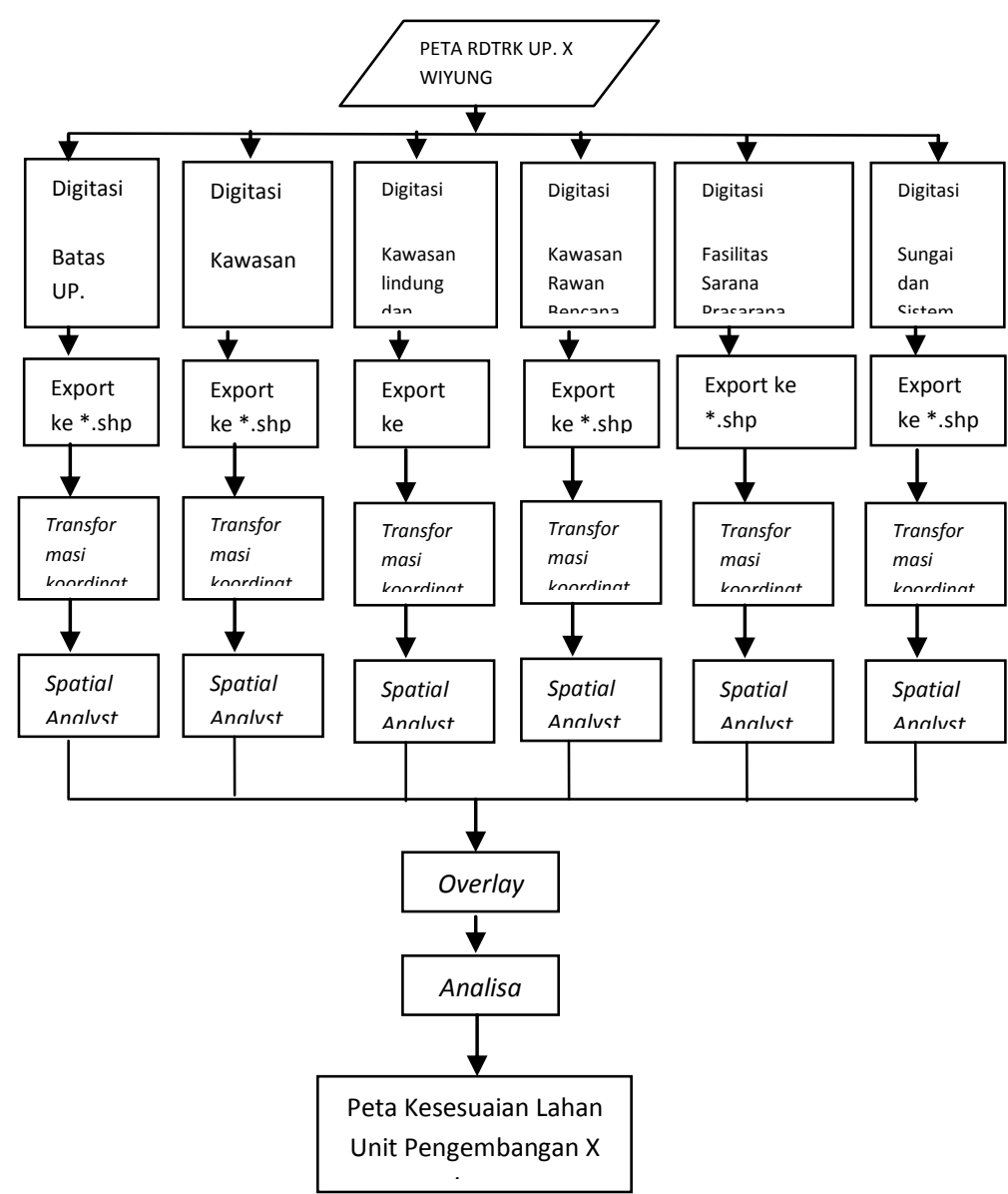

Gambar 4. Diagram Alir Pengolahan Data

Dalam tahapan pengolahan data peta RDTRK UP $\mathrm{X}$ wiyung dilakukan proses :

1. Digitasi Peta dengan mengklasifikasikan daerah kawasan pemukiman dan industri serta melakukan pemilihan data spasial yang digunakan dalam menganalisa tingkat kesesuaian lahan kawasan pemukiman dan industri yaitu topografi kemiringan tanah, tata letak lokasi, daerah rawan bencana, sarana dan prasarana, dan aksesbilitas.

2. Editing Peta dilakukan perubahan format menjadi format *shp guna memudahkan untuk pengolahan data peta tersebut. Selanjutnya dilakukan proses transformasi koordinat peta RDTRK yang pada awalnya menggunakan system koordinat Transvers Mercator 30 (TM 3) menjadi koordinat Universal Transvers Mercator (UTM). Agar Peta yang dihasilkan dapat digunakan secara umum. 
3. Analisa Pada tahap ini akan dilakukan analisa terhadap hasil dari pengolahan citra satelit ALOS dan peta RDTRK UP X Wiyung yang telah diolah dengan cara menggabungkan citra satelit ALOS dan peta RDTRK UP X Wiyung yang telah diolah untuk menentukan zonasi tingkat kesesuaian lahan kosong.

4. Hasil yang diperoleh dari penelitian ini yaitu peta zonasi tingkat kesesuaian lahan kawasan pemukiman dan industri unit pengembangan $X$ Wiyung Surabaya.

\section{HASIL DAN PEMBAHASAN}

\section{Koreksi Geometrik Citra dan SoF}

Hasil koreksi geometrik pada citra ALOS tahun 2010 yaitu nilai rata-rata $R M S_{\text {error }}$ sebesar 0,2018 piksel. Nilai Strength of Figure dari titik kontrol registrasi citra untuk citra ALOS tahun 2010 yang digunakan adalah 0,3883 . Menurut Purwadhi (2001), batas kesalahan pada proses koreksi geometrik untuk mendeteksi perubahan tutupan lahan yaitu 0.5 atau 1 piksel satu sama lain atau sekitar 10 meter (1piksel= 10×10meter) untuk citra ALOS. Sehingga jika pergeseran titik lebih dari batas toleransi maka koreksi harus diulang.

\section{Pemotongan Citra (Cropping)}

Setelah dilakukan koreksi citra dapat dilakukan pemotongan atau cropping sesuai dengan batas administrasi Unit Pengembangan $X$ Wiyung Kota Surabaya. Batas administrasi yang dijadikan acuan berasal dari Peta hasil RDTRK skala 1:5000 Unit Pengembangan X Wiyung tahun 2002.

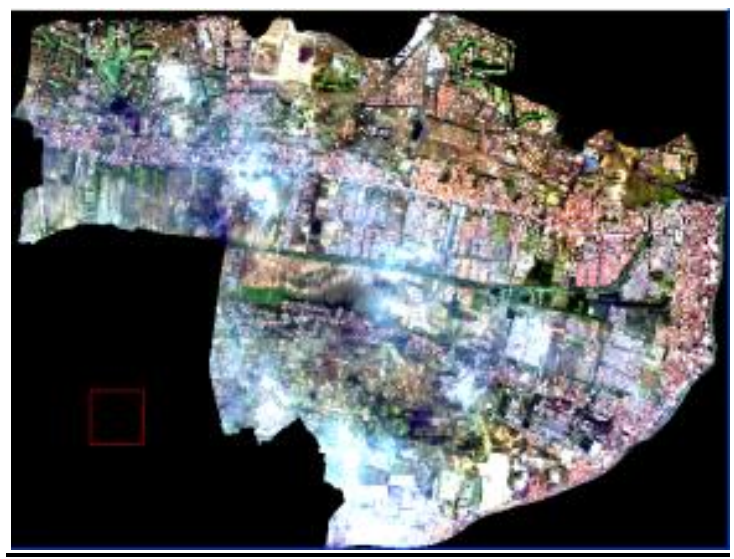

Gambar 5. Hasil cropping Citra ALOS Tahun 2010 Datum WGS '84 Proyeksi UTM Zona 49s

\section{Klasifikasi Terselia}

Pekerjaan klasifikasi dilakukan dengan metoda klasifikasi terselia tipe maximum likellihood dengan trainning sample 81 area. Jumlah kelas yang digunakan sejumlah 4 kelas tutupan lahan yaitu seperti dijelaskan dalam tabel di bawah ini :

\section{Tabel 1. Kelas Tutupan Lahan}

\begin{tabular}{ccc}
\hline No & Kelas & Warna \\
\hline 1 & Ladang & \\
2 & Sawah \\
3 & Badan Air \\
4 & Pemukiman \\
\hline
\end{tabular}

Berikut adalah peta hasil dari klasifikasi terselia menggunakan software $E N V I$ :

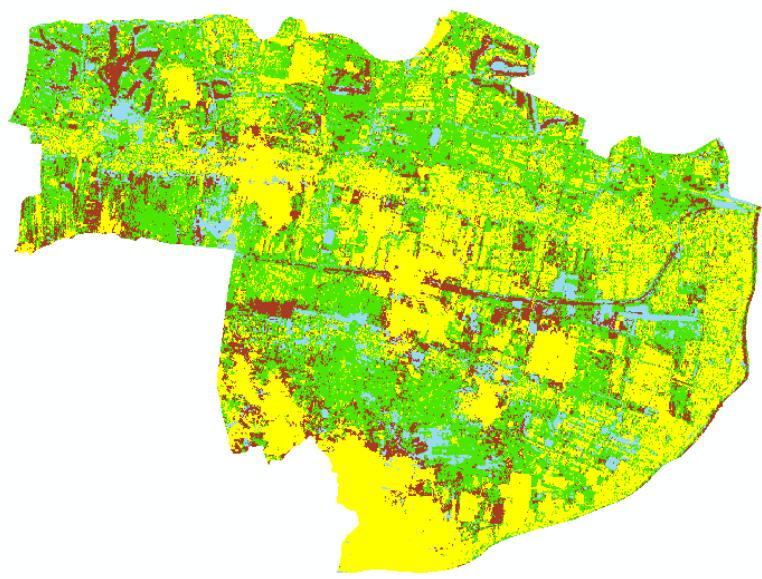

Gambar 6. Citra hasil klasifikasi menggunaka citra ALOS dengan sistem proyeksi UTM zona 49 S Datum WGS ‘84

\section{Uji Ketelitian Klasifikasi}

Uji ketelitian klasifikasi dilakukan dengan tujuan mengetahui ketelitian hasil klasifikasi, metode yang digunakan untuk perhitungan adalah confusion matrix. Sebelum dilakukan uji ketelitian diperlukan groundtruth atau survei lapangan untuk masing-masing kelas. Perhitungan uji ketelitian dengan metode confusion matrix ini dilakukan dengan software ENVI. Hasil dari confusion matrix citra satelit ALOS tahun 2010 dengan ENVI menunjukkan bahwa ketelitian klasifikasi sebesar 82,376 \%. Dengan hasil 
perhitungan ketelitian klasifikasi tersebut, bisa dianggap masuk toleransi karena diatas 80\%, sehingga hasil interpretasi memiliki kecocokan dengan data citra tersebut.

\section{Overlay}

Data-data yang sudah diolah kemudian dioverlaykan menggunakan software ArcGIS 10 dengan syarat sistem koordinat dari peta yang akan dioverlaykan harus sama. Data tersebut meliputi :

1. Peta vektor tutupan lahan hasil klasifikasi citra satelit ALOS tahun 2010.

2. Peta RDTRK (Rencana Detil Tata Ruang Kota) Unit Pengembangan X Wiyung Surabaya tahun 2009.

3. Peta Tematik Kelerengan Surabaya produk dari BAPPEKO tahun 2009

Proyeksi yang digunakan dalam peta ini yaitu sistem proyeksi Universal Transverse Mercator (UTM) Zona 49 S dengan datum WGS 1984. Skala peta yang digunakan yaitu 1 : 50.000. Unsur-unsur yang ada pada peta ini yaitu :

1. Badan Air (sumber : Citra Satelit ALOS tahun 2010)

2. Ladang (sumber Citra Satelit ALOS tahun 2010)

3. Permukiman (sumber : Citra Satelit ALOS tahun 2010)

4. Sawah (sumber : Citra Citra Satelit ALOS tahun 2010)

5. Batas Unit Pengembangan X Wiyung (sumber : Peta RDTRK UP. X Wiyung)

6. Kawasan Pemukiman dan Industri (sumber : Peta RDTRK UP. X Wiyung)

7. Kawasan Lindung (sumber : Peta RDTRK UP. X Wiyung)

8. Kawasan Penyangga (sumber : Peta RDTRK UP. $X$ Wiyung)

9. Kawasan Rawan Bencana (sumber : Peta RDTRK UP. X Wiyung)

10.Kelerengan Lahan (sumber : Peta Tematik Kelerengan Lahan Surabaya)

11.Sistem Drainase (sumber : Peta RDTRK UP. X Wiyung)

12.Sarana Prasarana (sumber : Peta RDTRK UP. X Wiyung)

13.Aksestabilitas (sumber : Peta RDTRK UP. X Wiyung)

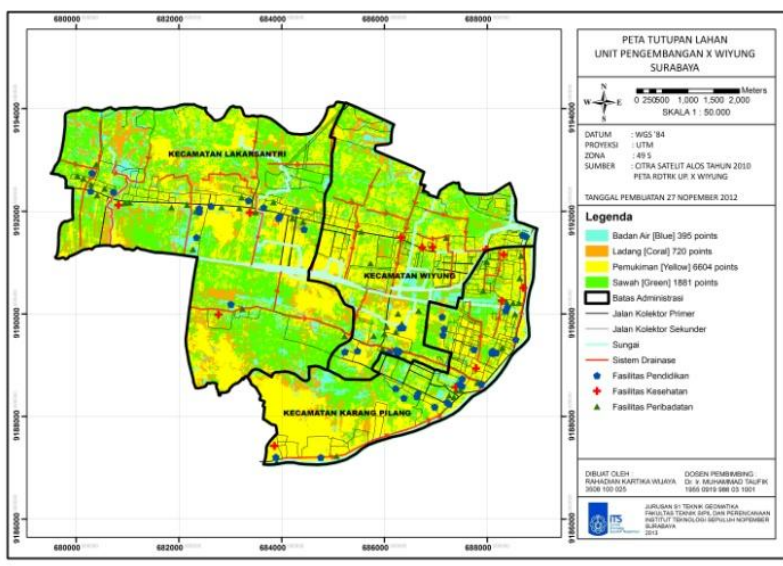

Gambar 7. Hasil Overlay Peta Tutupan Lahan dengan Peta RDTRK UP. X Wiyung Kawasan pemukiman dan Industri

\section{Analisa Tutupan Lahan}

Berdasarkan Tingkat kesesuaian lahan terhadap peruntukan kawasan dalam RDTRK UP X Wiyung yang disesuaikan dengan peraturan Direktorat Jenderal Penataan Ruang tahun 2008. Dalam pedoman kriteria teknis kawasan budidaya, Departemen Pekerjaan Umum, Jakarta, analisa kesesuaian lahan Kawasan peruntukan pemukiman dan industri menggunakan metode scoring yaitu dengan melakukan klasifikasi pada variabel- variabel penentu lokasi kawasan pemukiman dan industri berupa klasifikasi sesuai, kurang sesuai dan tidak sesuai. Pada penelitian ini klasifikasi menggunakan klasifikasi dengan cara tidak teratur, yaitu kelas interval ditentukan berdasarkan kelas interval yang dilakukan dengan ploting sesuai data yang ada. Selanjutnya melakukan pembobotan (scoring) untuk masing-masing variabel untuk menentukan tingkat kesesuaian lahan pergudangan terhadap parameter kawasan pergudangan. Tahapan ini pada dasarnya memberi nilai pada atribut suatu variabel, besar kecil skor ditentukan oleh nilai potensi yang tercermin dari variabel-variabel terpilih serta asumsi yang digunakan.

Skor akhir yang diperoleh dapat menggambarkan tingkat kesesuaian lahan kawasan pemukiman dan industri di UP $X$ Wiyung. semua variabel mempunyai penilaian dan bobot yang sama. Berikut tabel beserata analisis Kesesuian Lahan kawasan pemukiman dan industri dengan metode Scoring. 
Kawasan Pemukiman dan Industri UP. X Wiyung Berikut ini merupakan analisa kesesuaian lahan kawasan Pemukiman dan industri UP. X Wiyung :

Tabel 2. Analisa kesesuaian Lahan kawasan pemukiman UP. $X$ Wiyung

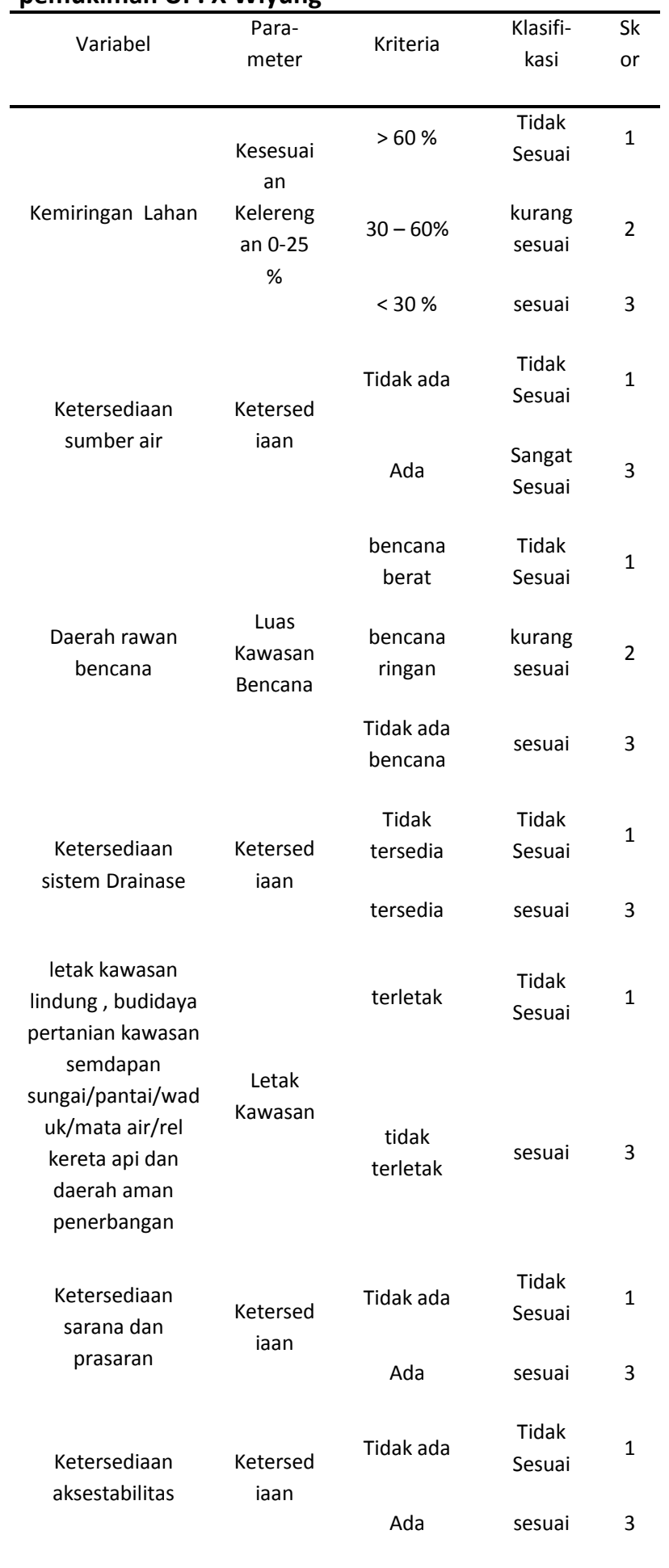

(Sumber : Junaidi, T. 1986 yang Termodifikasi)
Tabel 3 Analisa kesesuaian Lahan kawasan industri UP. X Wiyung

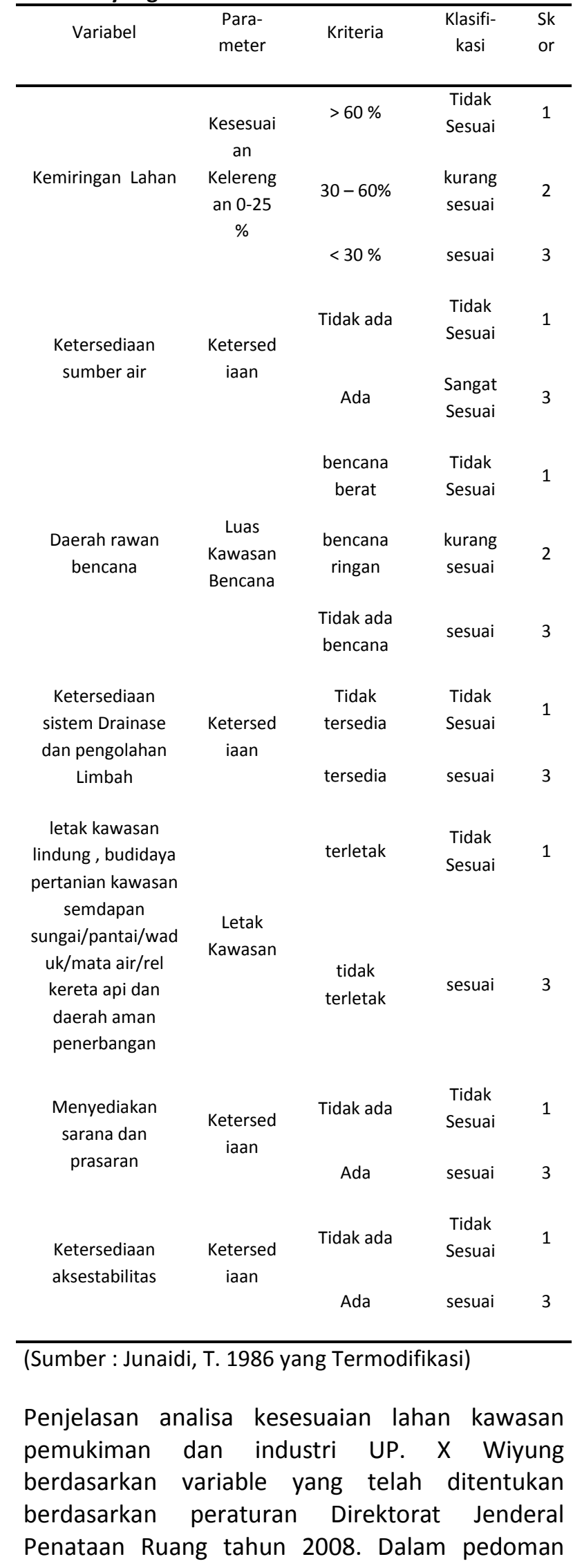


kriteria teknis kawasan budidaya, Departemen Pekerjaan Umum, Jakarta.

\section{Kemiringan tanah}

Kemiringan lahan/lereng banyak mempengaruhi terhadap tingkat kesesuaian lahan kawasan pemukiman dan Industri, semakin landai tingkat kemiringan tanah lahan akan semakin sesuai untuk lahan terbangun, kriteria yang ditentukan dari peraturan Direktorat Jenderal Penataan Ruang tahun 2008. Dalam pedoman kriteria teknis kawasan budidaya, Departemen Pekerjaan Umum, Jakarta. Adalah kurang dari 25\% sehingga kawasan pemukiman dan Industri yang terletak di UP. $X$ Wiyung Sesuai karena memiliki kemiringan tanah antara $10-15 \%$. Oleh karena itu variable Kemiringan tanah pada kawasan pemukiman dan Industri UP. X Wiyung diberi nilai 3 (sesuai)

\section{Ketersediaan Sumber Air}

Sistem penyediaan air bersih yang ada di UP. $X$ Wiyung berasal dari air PDAM yang disuplai dari Instalasi Pengolahan Air Minum (IPAM) Karang Pilang. Selama ini IPAM Karang Pilang mengambil bahan baku airnya dari air permukaan terdekat yaitu Kali Surabaya yang merupakan cabang dari Kali Brantas. Jaringan PDAM telah tersebar diseluruh UP. $X$ wiyung. Oleh karena itu variable Ketersediaan Sumber Air pada kawasan pemukiman dan Industri UP. X Wiyung diberi nilai 3 (sesuai).

\section{Daerah Rawan Bencana}

Menurut RDTRK UP $X$ Wiyung kawasan pemukiman mengalami bencana banjir saat musim penghujan dikarenakan pada kawasan pemukiman tersebut menerima banjir kiriman dari sisi utara ke selatan yang disebabkan oleh elevasi tanah di kawasan tersebut yang lebih rendah. Sedangkan untuk bencana kebakaran di UP. X Wiyung teridentifikasi terjadi pada kawasan perkampungan penduduk yang mempunyai kerapatan bangunan sangat tinggi sehingga perlu penataan ulang kawasan tersebut. Untuk itu kawasan pemukiman pada UP. X Wiyung diberi nilai 2 (kurang sesuai). Perlu adanya kajian lebih lanjut untuk menanggulangi bencana tersebut.

Pada kawasan industri untuk tingkat bencana tergolong lebih baik dari pada kawasan pemukiman karena kawasan industri terletak di sepanjang jalan mastrip sekitaran kali Surabaya dan memiliki system drainase yang baik dan kawasan industri di UP. X wiyung lebih tertata. Untuk itu kawasan pemukiman pada UP. $X$ Wiyung diberi nilai 3 (sesuai).

\section{Ketersediaan Drainase dan Pengolahan Limbah}

Pada UP. X wiyung terdapat 2 saluran primer yaitu Kali Surabaya dan Kali Makmur yang melintasi daerah Kelurahan Lakarsantri, Kelurahan Jeruk, Kelurahan Lidah Kulon, Kelurahan Lidah Wetan, Kelurahan Babatan, Kelurahan Balas Klumprik, Kelurahan Wiyung dan Kelurahan Jajar Tunggal, dan bertemu di saluran primer Kali Surabaya. selain itu, UP. X wiyung memiliki 19 Sub DAS (Daerah Aliran Sungai).

Tabel 4 Daerah Aliran Sungai UP. X wiyung

\begin{tabular}{cccc}
\hline No. & Sub DAS & No. & Sub DAS \\
\hline 1 & Sal. Kali Kedurus & 11 & Sal. Gungung Sari \\
2 & Sal. Lidah wetan Kulon & 12 & Sal. Bogangin I \\
3 & Sal. Jeruk & 13 & Sal. Bogangin Baru \\
4 & Sal. Babatan Indah & 14 & Sal. Kebraon \\
5 & Sal. Babatan Karangan & 15 & Sal. Kebraon Manis \\
6 & Sal. Wiyung & 16 & Sal. Prima Kebraon \\
7 & Sal. Menganti & 17 & Sal. Pondok Maritim \\
8 & Sal. Gemol Kedurus & 18 & Sal. Karang Klumprik Barat \\
9 & Sal. Gogor & 19 & Sal. Balas Klumprik \\
10 & Sal. Jajar Tunggal & & \\
\hline Sumber : Hasil Analisis RDTRK UP. X Wiyung Tahun 2009
\end{tabular}

Sehingga kawasan pemukiman dan industri yang terletak di UP. X Wiyung Sesuai karena memiliki sistem drainase yang merata. Oleh karena itu variable ketersediaan drainase pada kawasan pemukiman UP. X Wiyung diberi nilai 3 (sesuai). Namun untuk kawasan industri system pengolahan limbah belum tersedia dan perlu adanya penertiban terhadap lokasi kawasan industri yang berada di kawasan sempadan sungai. 
Oleh karena itu, variable ketersediaan drainase dan pengolahan limbah pada kawasan industri UP. X Wiyung diberi nilai 1 (tidak sesuai).

\section{Letak Kawasan}

Letak kawasan pemukiman UP. X wiyung tidak terletak di kawasan lindung maupun kawasan penyangga pertanian yang terletak disisi selatan UP. X Wiyung. Oleh karena itu variable Letak Kawasan pada kawasan pemukiman UP. X Wiyung diberi nilai 3 (sesuai).

Namun untuk kawasan industri UP. X Wiyung tidak memenuhi kriteria terletak di sekitar daerah sungai primer dan lokasi berdekatan dengan daerah pemukiman. Sehingga untuk variabel letak kawasan pada kawasan industry UP. X wiyung diberi nilai 1. (tidak sesuai)

\section{Ketersediaan Fasilitas sarana Prasarana}

Pada UP. X Wiyung memiliki kegiatan pendidikan yang membentuk pola tersebar pada pusat pusat kelurahan dan kecamatan, begitu juga dengan fasilitas kesehatan di antaranya rumah sakit, poliklinik, balai kesehatan dan puskesmas. Untuk sarana peribadatan mayoritas penduduk di UP. X Wiyung beragama Islam sehingga di dominasi masjid dan musolah yang tersebar merata. Sedangkan untuk sebaran fasilitas jasa perdagangan berada di sepanjang jalan akses yang ada di UP. X Wiyung. Oleh karena itu variable Ketersediaan Fasilitas sarana Prasarana pada kawasan pemukiman dan industri UP. $X$ Wiyung diberi nilai 3 (sesuai).

\section{Ketersediaan Aksestabilitas}

Pada UP. X wiyung Fungsi jalan arteri pada UP. Wiyung pada saat ini masih belum ada. Tetapi dengan adanya Rencana Transportasi yaitu dengan adanya rencana pembangunan Jalan Tol Surabaya Mojokerto, Jalan Lingkar Barat Dalam dan Lingkar Barat Luar, kaka fungsi jalan pada UP. Wiyung ini akan mengalami peningkatan fungsi maupun kelas jalan. Hal ini didukung dengan adanya jalan alternatif yaitu seperti jalan tembus tengah antar perumahan yang berada di sepanjang Jalan Wiyung - Menganti, maka jaringan jalan di UP. Wiyung akan mengalami suatu perubahan dan perkembangan dalam meminimalisasi permasalahan transportasi yang ada. Sehingga kawasan pemukiman dan industri yang terletak di UP. X Wiyung Sesuai karena telah tersedia aksestabilitas yang merata. Oleh karena itu, variable aksestabilitas pada kawasan pemukiman UP. X Wiyung diberi nilai 3 (sesuai).

\section{Tabel 5. Aksestabilitas UP. X Wiyung}

\begin{tabular}{cc}
\hline Kelas Jalan & Nama Jalan \\
\hline Arteri Primer & - \\
Arteri Sekunder & - \\
Kolektor Primer & $\begin{array}{c}\text { Jalan Gunung Sari, Jalan Mastrip, Jalan } \\
\text { Wiyung, Jalan Raya Menganti, }\end{array}$ \\
Kolektor Sekunder & Jalan Lakarsantri, Jalan Driyorejo. \\
Lokal Primer & Jalan Kebraon, Jalan Ksatrian, Jalan \\
Bangkingan, Jalan Lontar
\end{tabular}

Sumber : Hasil Analisis RDTRK UP. X Wiyung Tahun 2009

Tabel 6. Kelas Kesesuaian Lahan kawasan pemukiman dan industri UP. $X$ Wiyung

\begin{tabular}{cc}
\hline Kelas Kesesuaian & Penilaian Parameter \\
\hline $21-17$ & $\begin{array}{c}\text { UP. X Wiyung memiliki kesesuaian } \\
\text { lahan yang tinggi untuk kawasan } \\
\text { pemukiman dan industri }\end{array}$ \\
& UP. X Wiyung memiliki kesesuaian \\
& cukup untuk kawasan pemukiman \\
& dan industri, namun perlu adanya \\
$16-12$ & kajian dan perbaikan-perbaikan pada \\
& faktor yang mendukung untuk \\
(kurang Sesuai) & kawasan pemukiman dan industri. \\
& \\
& UP. X Wiyung memiliki kesesuaian \\
& yang rendah untuk kawasan \\
pemukiman karena kurangnya & faktor-faktor yang mendukung.
\end{tabular}

Dari hasil Analisa dengan menggunakan metode scoring untuk kawasan Pemukiman di UP. $X$ Wiyung termasuk kategori sesuai untuk kesesuaian lahan kawasan pemukiman dengan total nilai 20. Sehingga untuk pemanfaatan lahan 
kosong pada kawasan tersebut yang luasnya mencapai $1864,074 \mathrm{Ha}$ atau sebesar $58,52 \%$ dari luas keseluruhan kawasan peruntukan pemukiman yang direncanakan dalam RDTRK dapat realisasikan.

Sedangkan untuk kawasan industri di UP. X Wiyung termasuk kategori sesuai untuk kesesuaian lahan kawasan industri dengan total nilai 17. Namun tetap perlu ada kajian lebih lanjut mengenai variabel-variabel tersebut agar tingkat kesesuaian lahan pada kawasan tersebut lebih baik serta perlu adanya pengawasan terhadap pembangunan industri di kawasan tersebut yang telah direncanakan oleh Rencana Tata Ruang Wilayah Surabaya bahwa Kawasan Industri pada Kawasan tersebut merupakan kawasan industry non-polutif.

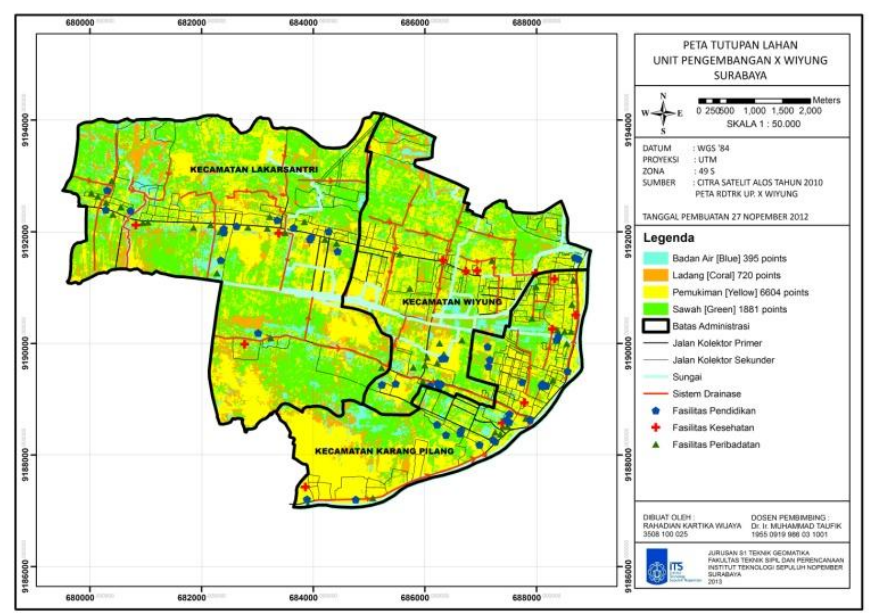

Gambar 8. Hasil Overlay Peta Tutupan Lahan dengan Peta RDTRK UP. X Wiyung

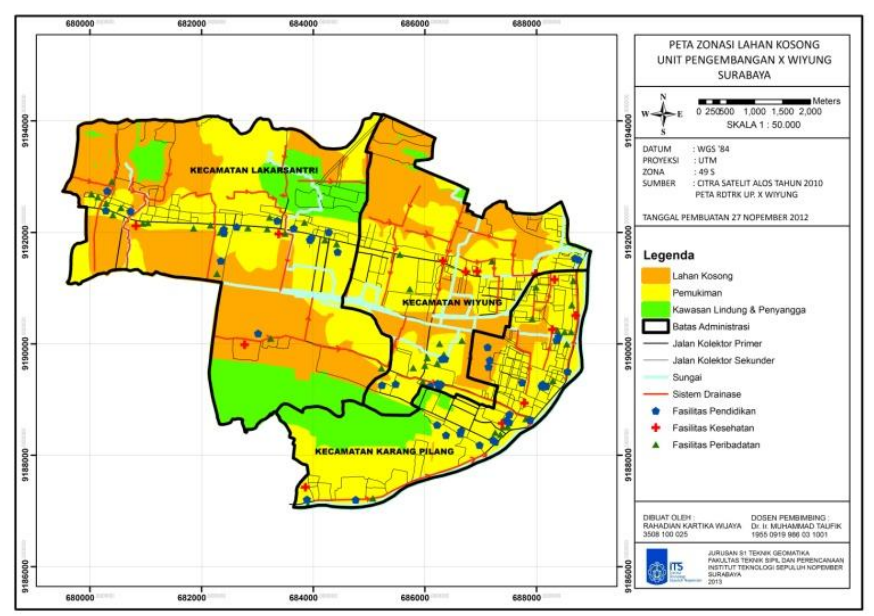

Gambar 9. Peta Zonasi Lahan Kosong Unit Pengembangan $X$ Wiyung

\section{KESIMPULAN DAN SARAN}

\section{Kesimpulan}

Kesimpulan yang diperoleh berdasarkan hasil penelitian ini antara lain :

1. Luas tutupan lahan wilayah penelitian unit Pengembangan $X$ Wiyung diperoleh dari hasil klasifikasi dari citra satelit ALOS tahun 2010 sebesar 4197,789 Ha yang terdiri dari 4 kelas yaitu : pemukiman seluas $1673,620 \mathrm{Ha}$ atau $39,86 \%$ dari luas keseluruhan, Sawah 1676,687 $\mathrm{Ha}$ atau 39,94 \% ladang 541,851 Ha atau $12.90 \%$ dan badan air $305.629 \mathrm{Ha}$ atau $7.28 \%$

2. Peruntukan kawasan pemukiman menurut RDTRK UP. X Wiyung memiliki Luasan sebesar 3183,631 Ha. Berdasarkan klasifikasi citra satelit ALOS tutupan lahan seluas $1321,372 \mathrm{Ha}$ untuk kelas pemukiman dan 1229,788 $\mathrm{Ha}$ untuk kelas sawah sedangkan kelas ladang ada sebesar 401,698 Ha dan kelas badan air sebesar 232,588 Ha sehingga lahan kosong yang belum termanfaatkan sebagai kawasan pemukiman sebesar $1864,074 \mathrm{Ha}$ atau sebesar $58,52 \%$.

3. Dari Hasil Analisa tingkat kesesuaian lahan Peruntukan Kawasan Pemukiman yang terdapat di Unit Pengembangan $X$ Wiyung didapatkan bahwa lokasi ini sesuai untuk peruntukan kawasan pemukiman serta dapat dimanfaatkan untuk memenuhi kebutuhan akan kawasan pemukiman.

4. Kawasan industri menurut RDTRK UP. $X$ Wiyung hanya tersebar pada kecamatan Karang Pilang dan memiliki Luasan sebesar 322,341 Ha. Namun, Berdasarkan hasil analisa yang didapat dari citra satelit ALOS dalam penelitian ini bahwa citra satelit ALOS tidak dapat digunakan dalam melakukan klasifikasi kawasan industri dikarenakan resolusi citra yang masih kurang mencukupi.

\section{Saran}

1. Diperlukan citra satelit yang memiliki resolusi lebih tinggi dari citra satelit ALOS untuk dapat menganalisa kawasan industri.

2. Perlu adanya tindakan dari pemerintah tentang permasalahan baik tentang bencana maupun tata letak lokasi kawasan yang terjadi 
di kawasan pemukiman pada unit pengembangan $X$ Wiyung.

3. Perlu adanya pengawasan dan kajian mengenai peruntukan lahan kosong oleh setiap pihak yang terkait agar tidak terjadi penyimpangan terhadap penggunaan lahan di Unit Pengembangan $X$ Wiyung.

\section{DAFTAR PUSTAKA}

Ardhiaty, L Niken. 2002. Konsep Penerapan Insentif Deisntif Untuk Penanganan Lahan Kosong . Tugas Akhir, Departemen Teknik Planologi Institut Teknologi Bandung.

Ariastita, G.P. Dan navastara. A.M. 2009. Buku Ajar Tata Guna Dan Pengembangan Lahan. Surabaya : Program Studi Perncanaan Wilayah Dan Kota. Institut Teknologi Sepuluh Nopember Surabaya.

Ariastita, G.P. 2004. Lahan kosong : Potensi Konflik Pertanahan Di Perkotaan Dan Resolusinya, Surabaya

Atmapradana, Tedi. 2010. Evaluasi Rencana Detail Tata Ruang Kota (RDTRK) Surabaya Unit Pengembangan (UP) Satelit Menggunakan Citra Satelit Quickbird. Surabaya : Tugas Akhir Program Studi Teknik Geomatika ITS.

Bourne, S Larry.1982. Internal Structure Of The City. Oxford University Press, Washington.

Danoedoro, P. 1996. Pengolahan Citra Digital Teori Dan Aplikasinya Dalam Bidang Pengindraan Jauh. Fakultas Geografi, Universitas Gadjah Mada. Yogyakarta.

Darin-Drabkin, Haim. 1977. Land Policy and Urban growth. Pergamon Press.

Direktorat Jendral Penataan Ruang. 2008. Modul Terapan. Pedoman Kriteria Teknis Kawasan Budi Daya. Departemen Pekerjaan Umum, Jakarta.

Ginarjar, W.R. 2010. Klasifikasi Perubahan Lahan Dalam Rencana Detail Tata Ruang Kota (RDTRK) Surabaya Unit Pengembangan (UP) VIII Satelit Dengan Menggunakan Citra Satelit Quickbird. Surabaya : Tugas Akhir Program Studi Teknik Geomatika ITS.

Hallet, graham. 1979. Urban Land Economic. London. The Macmillan Press Itd.

Johara, T, J. 1999. Tata Guna Tanah Dalam Perencanaan Pedesaan, Perkotaan, Dan Wilayah, Bandung, ITB.

Kivell, Philip.1993. Land And The City Pattern And Processes Of Urban Change. Routledge, New York.

Lillesand, T. M., And Kiefer, R.W. 1994. Remote Sensing And Image Interpretastion. Jhon Wiley \& Son inc, New York.
Pemerintah Kota Surabaya, 2005. Naskah Raperda RTRW Revisi Edisi 20-11-2005, Hasil Pembahasan Pansus RTRW November 2005. Pemerintah kota surabaya.

Pemerintah Kota Surabaya, 2009. Laporan Akhir Rencana. Rencana Detail Tata Ruang Kota (RDTRK) Unit Pengembangan (UP) $X$ Wiyung. Badan Perencanaan Dan Pembangunan Kota (BAPPEKO) Surabaya.

Purwadhi, S.H. 2001. Interpretasi Citra Digital. Gramedia Widiasarana Indonesia. Yogyakarta.

Prahasta, E. 2001. Sistem Informasi Geografi. Edisi Revisi, Cetak Kedua. C.V. Informatika : Bandung.

Undang-Undang no. 5 Tahun 1960 Tentang Peraturan Dasar Pokok-Pokok Agraria.

http://www.eorc.jaxa.jp dikunjungi pada tanggal 28 agustus 2012 jam 19.30 WIB 